(c) American Dairy Science Association, 2005.

\title{
Cross-Infection Between Cats and Cows: Origin and Control of Streptococcus canis Mastitis in a Dairy Herd
}

\author{
L. L. Tikofsky ${ }^{1}$ and R. N. Zadoks ${ }^{1,2}$ \\ ${ }^{1}$ Quality Milk Production Services, and \\ ${ }^{2}$ Department of Food Science, Cornell University, Ithaca, NY 14850
}

\begin{abstract}
Group G streptococci in animals usually belong to the species Streptococcus canis and are most commonly found in dogs and cats. Occasionally, Strep. canis is detected in milk from dairy cows. An outbreak of Strep. canis mastitis in a dairy herd is described. Based on results from bacterial culture and ribotyping, a cat with chronic sinusitis was the most likely source of the outbreak. Subsequent cow-to-cow transmission of Strep. canis was facilitated by poor udder health management, including use of a common udder cloth and failure to use postmilking teat disinfection. Infected cows had macroscopically normal udders and milk, but significantly higher somatic cell counts than Strep. canis-negative herd mates. The outbreak was controlled through antibiotic treatment of lactating cows, early dry-off with dry cow therapy, culling of infected animals, and implementation of standard mastitis prevention measures. Cure was significantly more likely in dry-treated cows $(87.5 \%)$ and cows treated during lactation (67\%) than in untreated cows (9\%). Whereas mastitis due to group G streptococci or Strep. canis in dairy cows is usually limited to sporadic cases of environmental (canine or feline) origin, this case study shows that crossing of the host species barrier by Strep. canis may result in an outbreak of mastitis if management conditions are conducive to contagious transmission. In such a situation, measures that are successful in control of Strep. agalactiae can also be used to control Strep. canis mastitis.

(Key words: Streptococcus canis, mastitis, host species barrier, group G streptococcus)
\end{abstract}

Abbreviation key: BMSCC = bulk milk somatic cell count, DCT = dry cow treatment, GGS = group G streptococcus, LCT = lactating cow treatment, MRSA = methicillin-resistant Staphylococcus aureus, QMPS = Quality Milk Production Services.

Received March 7, 2005.

Accepted April 12, 2005. Corr.
edu.

\section{INTRODUCTION}

Streptococci are a common cause of mastitis in dairy cows. In many areas, contagious mastitis caused by Streptococcus agalactiae has largely been controlled (Loeffler et al., 1995; Andersen et al., 2003), but other streptococci, specifically Streptococcus dysgalactiae and Streptococcus uberis, continue to be highly prevalent throughout the world (Wang et al., 1999; Zadoks et al., 2004). Identification of streptococcal species in mastitis diagnostics is usually based on hemolytic patterns, esculin splitting, and the CAMP reaction (National Mastitis Council, 1999). Serological grouping in accordance with the Lancefield system can also be used for typing of some streptococcal species from milk, most importantly for group B streptococci or Strep. agalactiae (Facklam, 2002). In addition, group G streptococci (GGS) are occasionally found in bovine milk samples.

Mastitis caused by GGS in dairy cows is relatively rare. In herd surveys from Iowa and New York State, the prevalence was $0.7 \%$ of 455 streptococcal cultures from 72 herds (McDonald and McDonald, 1976), 4 of 250 dairy herds (1.6\%) (Hamilton and Stark, 1970), and 125 of 105,083 surveyed cows $(0.1 \%)$ (Wilson et al., 1997). However, herd outbreaks due to GGS have been reported from many places, including Washington, DC (Miller and Heishman, 1940); Ontario, Canada (Barnum and Fuller, 1953); Denmark (Romer, 1948); New York (Hamilton and Stark, 1970); Pennsylvania (Eberhart and Guss, 1970); Israel (Bergner-Rabinowitz et al., 1981); Louisiana (Watts et al., 1984); The Netherlands (O. C. Sampimon, personal communication, 2003); and Italy (P. Moroni, personal communication, 2003). In 1986, the name Streptococcus canis was coined (Devriese et al., 1986) to describe GGS found in dogs and cattle. Animal GGS or Strep. canis differed in physiological, biochemical, and DNA hybridization characteristics from human GGS isolates which belong to the species Strep. dysgalactiae spp. equisimilis (Devriese et al., 1986). In fact, Strep. canis is more closely related to Streptococcus pyogenes or group A streptococcus than to GGS of humans (Facklam, 2002). In dogs and cats, Strep. canis is found on skin and mucosa of asymptomatic carriers and in many pathological conditions, in- 
cluding infections of the skin, urogenital, and respiratory tract, polyarthritis, abortion, septicemia, canine streptococcal toxic shock syndrome, and necrotizing fasciitis (Devriese et al., 1986; DeWinter et al., 1999; Hassan et al., 2003).

In this paper, we describe an outbreak of bovine mastitis caused by Strep. canis in a New York State dairy herd. The source of infection and routes of pathogen transmission are identified through bacteriology, molecular typing of GGS isolates, and analysis of herd management. The impact on affected cattle and the outcome of antibiotic treatments and management changes that were instituted to curb the outbreak are presented. This case study serves both as a suggestion on how to deal with Strep. canis in dairy cattle, and as an example of the combination of traditional herdhealth approaches with modern DNA-based methods for problem solving in a situation where crossing of the host-species boundary by a pathogen resulted in an unusual disease outbreak.

\section{MATERIALS AND METHODS}

\section{Case History}

In April 1999, Quality Milk Production Services (QMPS) personnel were requested to visit a dairy herd in central New York State for the first time to perform a whole-herd mastitis screening survey. The herd, consisting of 90 lactating head of Holstein-Friesian cattle with mean 305-d milk production of $6700 \mathrm{~kg} / \mathrm{cow}$, was in danger of losing its milk market because 2 of the last 4 official bulk milk somatic cell counts (BMSCC) were greater than 750,000 cells $/ \mathrm{mL}$. Bulk milk SCC had been $173,000 / \mathrm{mL}$ in December 1998, but counts had risen steadily since that time. The most recent BMSCC was $1,800,000 / \mathrm{mL}$. Standard plate count was $41,000 \mathrm{cfu} / \mathrm{mL}$.

The herd was housed in a tie-stall barn with concrete floors. Stalls were covered with rubber mats and minimal amounts of old hay. The milking system included a 5.08 -cm (2-inch) pipeline around the barn with 8 milking units. Cows were milked twice daily by the producer and his wife. Cows' teats were forestripped and then washed with water and a common towel. Teats were not dried before attachment of the milking unit. Postmilking teat dip was not applied, and gloves were not worn by the producer or his wife. Cows were milked once a day for $3 \mathrm{~d}$ before dry off and then treated in each quarter with a long-acting penicillin-dihydrostreptomycin treatment. The herd had been closed for $40 \mathrm{yr}$ and had always been housed at the same location. Several cats had access to the barn.

A second visit followed in May 1999. Bulk milk SCC on the latest test was $560,000 / \mathrm{mL}$. Quarter samples for bacteriologic culture were collected from those lactating cows that were diagnosed with GGS at the whole herd survey in April. From the remaining 50 cows, composite cow milk samples were collected. In addition, swabs or samples were collected from milking unit inflations, nasal secretions, and hand surfaces of the producer's wife, udder wash towels, dip cups, and feline nasal and anal secretions. Personnel from QMPS returned to the herd in July and October 1999, for whole herd surveys. Bulk milk SCC were $560,000 / \mathrm{mL}$ and $470,000 / \mathrm{mL}$, respectively, at those surveys. Because BMSCC was consistently below the legal limit and the producer planned to sell the herd in 2000, no further treatments or surveys were undertaken.

\section{Milk Samples, Bacteriology, and SCC}

Composite milk samples from each lactating cow were collected aseptically into sterile vials, in accordance with National Mastitis Council guidelines, at the morning milking. Samples were cooled rapidly and transported to the laboratory for immediate bacteriologic culture. Aliquots $(0.01 \mathrm{~mL})$ of each sample were plated on trypticase soy agar plates containing 5\% sheep blood and $0.1 \%$ esculin (Becton Dickinson, Sparks, MD). Plates were incubated aerobically at $37^{\circ} \mathrm{C}$ and examined for growth at 24 and $48 \mathrm{~h}$. Colonies were presumptively identified as streptococci by colony morphology, hemolytic patterns, and esculin reaction, and were confirmed by Gram stain and catalase-negative reaction. Representative colonies were tested for the CAMP reaction. Biochemical tests were performed on representative isolates with the API 20 Strep system (BioMèrieux, Hazelwood, MO), and serologic grouping was accomplished on all streptococcal isolates with the PathoDx latex agglutination system following the manufacturer's recommendations (Diagnostic Products Corporation, Los Angeles, CA). Based on this method, isolates could be identified as GGS, without differentiation between Strep. canis and Strep. dysgalactiae spp. equisimilis. Swab samples were inoculated in Todd-Hewitt broth upon collection and taken back to the laboratory for processing within a few hours. In the laboratory, samples were incubated for 3 to $4 \mathrm{~h}$ in a water bath at $37^{\circ} \mathrm{C}$. Swabs were subsequently streaked onto trypticase soy agar plates containing 5\% sheep blood and $0.1 \%$ esculin. Plates were processed and evaluated as described for milk samples.

Additional composite milk samples that were collected during the second herd survey (May 1999) were used to measure SCC (Fossomatic FC; Foss, Eden Prairie, $\mathrm{MN})$. Antibiotic sensitivity of a limited number of isolates $(n=5)$ was determined using the Kirby-Bauer agar disk diffusion method in accordance with standards from the National Committee for Clinical Labora- 
tory Standards (NCCLS, 1997). Antibiotics tested were amoxicillin, cephalotin, novobiocin, oxacillin, penicillin/ novobiocin, penicillin, pirlimycin, and tetracycline. Based on the diameters of the inhibition zones, bacteria were classified as resistant, intermediately resistant, or susceptible.

\section{Interventions}

Because of the impending loss of the milk market, a decision was made to treat or cull all cows that were infected with GGS. Seven cows were culled immediately because of poor production or infertility. Cows due to dry off $(n=7)$ were treated in all 4 quarters for 3 consecutive milkings with $62.5 \mathrm{mg}$ of amoxicillin and then abruptly dried off with 1,000,000 IU of penicillin and $1 \mathrm{~g}$ of dihydrostreptomycin (dry cow treatment; DCT). Lactating cows $(\mathrm{n}=18)$ were treated with 62.5 mg of amoxicillin in all 4 quarters for 3 consecutive milkings (lactating cow treatment; LCT). Postmilking teat dipping with $0.5 \%$ iodine was also instituted. After the second survey (July 1999), 2 additional cows were treated with amoxicillin based on these culture results, and 1 additional cow with GGS was culled from the herd. Eleven cows infected with GGS remained in the herd but did not receive treatment. Allocation of treatment was decided by the farmer and was not based on formal randomization. After the second survey, use of the common towels was discontinued, and individual paper towels were used for udder preparation.

\section{Molecular Typing}

During routine bacteriology, isolates were identified as GGS based on serology. To determine whether GGS isolates belonged to the species Strep. canis, PCR using species-specific 16S rDNA as target (Hassan et al., 2003) was used to test 1 feline isolate and 12 bovine isolates. Strain typing of confirmed Strep. canis isolates was performed by means of automated ribotyping using the RiboPrinter Microbial Characterization system (Qualicon, Wilmington, DE) and restriction enzymes EcoRI or PvuII. Based on results for this selection of all GGS isolates in combination with the herd situation, typing of additional isolates was not deemed necessary.

\section{Statistical Analyses}

For analysis of SCC data, cows were grouped based on culture results, and SCC were log-transformed. Cows were classified as 1) infected with GGS, 2) infected with other major pathogens, 3 ) infected with Corynebacterium bovis, 4) infected with other minor pathogens (Staphylococcus spp.), or 5) culture-negative. Group as- signment was hierarchical, i.e., any sample with GGS was assigned to group 1, irrespective of presence of other bacterial species; any sample without GGS but with other Streptococcus species or Staphylococcus aureus was considered group 2, irrespective of presence of minor pathogens, etc. Comparisons of SCC between groups were done using box and whisker plots and 1way ANOVA. Cure rates for LCT and DCT were analyzed by logistic regression and $\chi^{2}$ analysis. Because several cells in the $\chi^{2}$ analysis had values less than 5, Fisher's Exact tests were also performed. Significance was declared at $P<0.05$. All analyses were done in Statistix version 8.0 (Analytical Software, Tallahassee, FL).

\section{RESULTS}

\section{Bacteriology}

At the first survey (April 1999), 46 of 90 cows (51\%) cultured positive for GGS. Sixteen cows (18\%) were infected with Staph. aureus. Six cows had concurrent infections with both organisms and are included in both counts. Results of the second survey (May 1999) indicated that 17 of $77(22 \%)$ lactating cows were infected with GGS. Cultures positive for GGS were identified from 1 milking unit liner and from nasal secretions from a cat with chronic sinusitis. The samples from the producer's wife, collected because she suffered from chronic pharyngitis and sinusitis, tested negative for GGS in tests performed by QMPS (skin swabs, nasal secretion) or by the family physician (pharyngeal swab). At the third and fourth surveys (July and October 1999) 19 and 11 cows, respectively, were culture-positive for GGS. Moreover, GGS was consistently isolated from nasal secretions from the cat with chronic sinusitis that had tested positive in May. For analysis of cure data, quarters that were positive for GGS before treatment and had 2 negative cultures at 2 subsequent surveys after treatment were considered cured.

\section{SCC}

Udders of cows infected with GGS were normal on palpation and none of these cows showed evidence of clinical mastitis. Average logSCC was 6.7 (equivalent to 4.8 million cell $\mathrm{s} / \mathrm{mL}$ ) for GGS-positive milk samples ( $\mathrm{n}=16$ ), 6.2 (equivalent to 1.5 million cells $/ \mathrm{mL}$ ) for milk samples containing other major pathogens $(n=8), 6.0$ (equivalent to 1 million cell $\mathrm{s} / \mathrm{mL}$ ) for milk samples that only contained $C$. bovis $(\mathrm{n}=27$ ), 5.8 (equivalent to 631,000 cells $/ \mathrm{mL}$ ) for milk samples with other minor pathogens $(n=7)$, and 5.5 (equivalent to 353,000 cells/ $\mathrm{mL})$ for culture-negative milk samples $(\mathrm{n}=20)$. LogSCC for GGS-positive samples was significantly higher than 


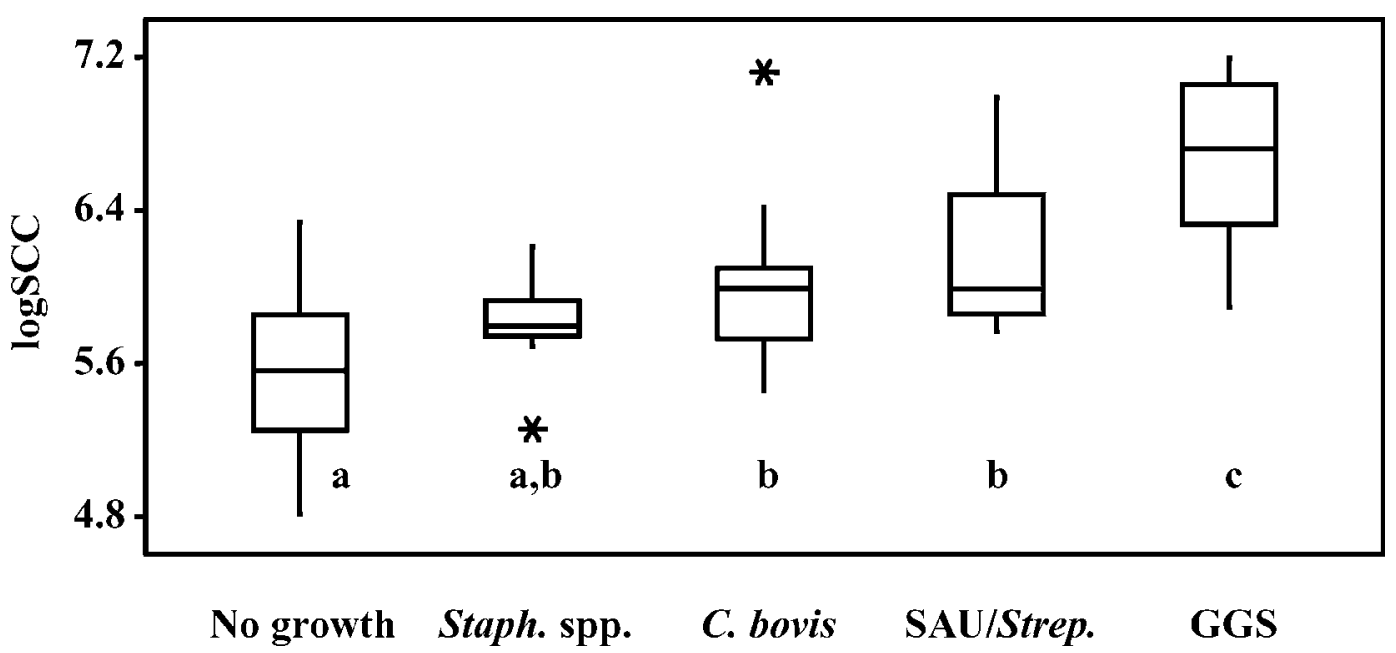

Figure 1. Boxplot of logSCC by culture status of composite cow milk samples. Different letters indicate that average logSCC is significantly different between groups $(P<0.05)$. Culture status: No growth $=$ culture-negative; Staph. spp. = positive for other minor pathogens (Staphyloccoccus spp.); C. bovis = positive for Corynebacterium bovis (irrespective of presence of other minor pathogens); SAU/Strep. = positive for Staphylococcus aureus or Streptococcus species other than group G streptococci (GGS) (irrespective of presence of other minor pathogens); GGS = positive for GGS (irrespective of presence of other pathogens). Bottom of each box represents first quartile; central line indicates median; top of box represents third quartile; and whiskers indicate range. Possible outliers, defined as values that are outside the box boundaries by more than 1.5 times the size of the box, are indicated by an asterisk.

for any other type of sample, and logSCC for culturenegative samples was significantly lower than for samples harboring GGS, other major pathogens, or C. bovis (Figure 1).

\section{Molecular Typing}

One feline isolate and 12 bovine isolates of GGS were tested by PCR and confirmed to be Strep. canis. Among the bovine Strep. canis isolates, which originated from quarter milk samples of 12 different cows, 1 ribotype was identified by means of $E c o R I$ ribotyping. The same ribotype was obtained for Strep. canis isolated from nasal secretion of the cat with chronic sinusitis. Ribotyping of a feline and bovine isolate with PvuII yielded indistinguishable patterns too (Figure 2). Ribotype images for all isolates used in this study are publicly available in the searchable PathogenTracker database (www.pathogentracker.net). Ribotypes are identified by a code (e.g., 116-783-3) consisting of instrument ID (i.e., 116) and pattern ID (e.g., 783-3).

\section{Treatment and Cure}

Antibiotic sensitivity was determined for the feline isolate and 4 bovine isolates. Resistance was not detected. Because the outbreak appeared to result from contagious transmission of one strain, no additional sensitivity testing was done. Thirteen of 20 cows receiving LCT with amoxicillin were cured (65\%), as were 6 of $7(87.5 \%)$ cows receiving DCT with amoxicillin and penicillin-dihydrostreptomycin. Eleven infected cows remained in the herd but were not treated. One of those cows $(9.0 \%)$ showed a spontaneous cure whereas the rest cultured positive on subsequent samples. Lactating cow treatment and DCT did not differ significantly from each other in probability of cure $(P=0.6)$, but both were significantly more likely to result in cure than no treatment $(P<0.001)$.

\section{DISCUSSION}

In this case study, we describe an outbreak of Strep. canis mastitis in a dairy herd that was most likely initiated by cross-host-species transmission of Strep. canis from a cat with chronic sinusitis to a cow, and subsequently spread from cow to cow in a contagious manner as a result of poor milking hygiene. The outbreak was controlled through implementation of routine mastitis prevention measures, i.e., use of singleuse udder towels and postmilking teat disinfection (aimed at a reduction in the incidence of new infections), in combination with culling, dry-off, and lactational treatment of infected cows (aimed at reduced prevalence of infection). Reduction in prevalence was needed to decrease exposure to GGS and incidence of new cases, and to bring BMSCC back down to a level that allowed for shipping of milk.

Streptococcus canis mastitis in dairy cows is relatively rare but its occurrence has been reported from 


\begin{tabular}{|c|c|c|c|c|}
\hline $\begin{array}{l}\text { Host } \\
\text { species }\end{array}$ & Source & Enzyme & RiboPrint pattern & $\begin{array}{l}\text { Number of } \\
\text { isolates typed }\end{array}$ \\
\hline Cat & Nasal secretion & EcoRI & | | I & 1 \\
\hline Cow & Milk & EcoRI & 111 & 12 \\
\hline Cat & Nasal secretion & PvuII & 11 & 1 \\
\hline Cow & Milk & $P v u \mathrm{II}$ & | | & 1 \\
\hline
\end{tabular}

Figure 2. Ribotyping results for Streptococcus from a cat with chronic sinusitis and cows with mastitis on a dairy farm.

several countries and continents around the world. In some cases, anecdotal information specifically implies a role for a canine source (barn dog licking cows' teats; personal communication to RNZ from a Dutch veterinarian, 2003). Based on strain typing, we showed that a cat may have been the source of the outbreak reported here. The cat had chronic sinusitis that predated the mastitis outbreak, had access to the cows, and shed Strep. canis. It is also possible that the cat became infected through consumption of raw cows' milk, but because the cat had sinusitis before the outbreak, we think it more likely that the cat infected the cows than vice versa. Although many bacterial species or strains are more or less host-specific, crossing of host species boundaries has been described for several pathogens of animals and humans. For example, Staph. aureus, in particular methicillin-resistant Staph. aureus (MRSA), has been transmitted between humans and animals in both directions. Dogs (Cefai et al., 1994) and cats (Scott et al., 1988) can act as a source of MRSA carriage in humans, and humans can be a source of MRSA for animals. An outbreak of mastitis in dairy cows caused by MRSA has been attributed to introduction by a milker (Devriese and Hommez, 1975). Host-adapted strains have also been described for Strep. agalactiae, another udder pathogen of dairy cows (Bisharat et al., 2004; Sukhnanand et al., 2005). Some clones of Strep. agalactiae are predominantly found in humans, whereas different clones are found in milk from dairy cows (Sukhnanand et al., 2005). However, human strains of Strep. agalactiae have been found in other animals, i.e., dogs and cats, suggesting an epidemiological connection and possible transfer of bacteria across host species (Yildirim et al., 2002). Thus, although a host species barrier exists, pathogens may infect species that are not their natural host.

Theoretically, the fact that ribotyping results were identical for all cows could be the result of infection of each cow individually by the cat. However, it seems far more likely that the host species barrier was crossed once, and that subsequent cow-to-cow transmission of Strep. canis occurred. Two obvious shortcomings in milking time hygiene that may have contributed to pathogen spread are the use of a communal udder cloth and the failure to use postmilking teat disinfection. An outbreak of streptococcal mastitis in the absence of postmilking teat disinfection due to another streptococcal species that is not contagious under good management conditions, Strep. uberis, has been described before (Zadoks et al., 2001). In that outbreak, as in the current case study, mastitis-causing streptococci were isolated from inflations, implying that the milking machine, like the communal udder cloth, may act as a fomite for transmission (Zadoks et al., 2003). It has been known for decades that postmilking teat disinfection can curb the transmission of many Streptococcus species (Neave et al., 1969; Eberhart et al., 1983). Because speciation and strain typing results were the same for all samples that were characterized with molecular methods, confirmation of all GGS isolates as Strep. canis and ribotyping of all isolates was not deemed necessary.

The incidence of GGS infections in humans is increasing in many parts of the world (Lewthwaite et al., 2002; Sylvetsky et al., 2002; Ikebe et al., 2004). Our interest in this outbreak of GGS mastitis in dairy cows was partially ignited by the possibility of milk acting as a source of GGS in people. Human and animal GGS can each cause chronic pharyngitis and sinusitis in their respective hosts (Ikebe et al., 2004). On the farm, chronic sinusitis/pharyngitis was present in a human and a cat; hence, samples from both hosts were analyzed. Only the cat was shown to carry GGS and more specifically, Strep. canis. In general, GGS from dairy cows belong to the species Strep. canis (Devriese et al., 1986; unpublished results from our laboratory) whereas GGS in humans rarely does (Zaoutis et al., 1999; Woo et al., 2003; Ikebe et al., 2004). A few exceptions to 
this rule are cases of Strep. canis septicemia in elderly people that were bitten by a dog (Takeda et al., 2001) or that had a condition predisposing them to secondary infection (Bert et al., 1997; Whatmore et al., 2001).

There is no known public health impact of Strep. canis in cattle but infections with the pathogen have a serious impact on udder health and milk quality. Clinical mastitis and damage to udder secretory tissue because of GGS infection is variable and ranges from no gross alterations of milk to severely clotted samples (Hamilton and Stark, 1970). Leukocytosis appears to be a common finding (Miller and Heishman, 1940; Barnum and Fuller, 1953; Eberhart and Guss, 1970; Watts et al., 1984). In the outbreak reported in this case study, gross abnormalities of the udder were not noted but SCC of GGS-infected cows was significantly higher than that of cows that did not have GGS, including cows that had infections with other major pathogen species such as Staph. aureus or nonagalactiae streptococci other than GGS. In previous studies, response of GGS infections to intramammary antibiotic therapy has been variable (Miller and Heishman, 1940; Barnum and Fuller, 1953; Eberhart and Guss, 1970; Watts et al., 1984) despite demonstration of good susceptibility of the bacteria to penicillin in vitro (Devriese et al., 1986; Libertin et al., 1988). Hamilton and Stark (1970) state that "the infected quarters were readily cured with commercially prepared mastitis infusions containing procaine penicillin G and dihydrostreptocmycin" without specifying dose or length of treatment or number of treated cases. Good cure with procaine penicillin $\mathrm{G}$ was also reported in a Pennsylvania herd (Eberhart and Guss, 1970). In contrast, Watts et al. (1984) reported only $24 \%$ cure for LCT with a penicillin-based product, whereas 55 and $70 \%$ cure was achieved with cephalosporin as LCT or $\mathrm{DCT}$, respectively. In the herd described in the current paper, treatment with amoxicillin and (in the case of DCT) penicillin-dihydrostreptomycin was successful in the majority of cases. Treatment was warranted because of the impending loss of the milk market; and resulted in reduction of BMSCC and return of the herd to an economically viable status.

\section{CONCLUSIONS}

To summarize, we showed how strain typing was used to demonstrate contagious transmission of a pathogen, and that a cat was the most likely source of an unusual outbreak of mastitis in a dairy herd. We also demonstrated how cow and herd level data were used to identify contributing causes to the problem, such as poor milking time hygiene, as well as opportunities for control of the disease outbreak. Through culling of cows with poor prognosis for cure and treatment of cows during lactation or at dry off, infection prevalence and BMSCC were reduced. The decrease in prevalence, combined with management measures aimed at a decrease in infection incidence through diminished pathogen transmission, resulted in return of the herd to an udder health status and milk quality level that met the producer's needs and industry standards. Thus, this case study shows how routine bacteriology and analysis of milking management, combined with use of molecular methods, can help resolve disease outbreaks, and specifically how an outbreak of Strep. canis mastitis in a dairy herd may be handled.

\section{ACKNOWLEDGMENTS}

We would like to thank the farm family for their willingness to cooperate in this study. In addition, we acknowledge the support of QMPS field staff in sample collection and Ruben Gonzalez and Mike Zurakowski for bacteriological analyses. The Pathogen Tracker 2.0 database online public subtyping database is supported by USDA Special Research Grants 2001-34459-10296 and 2002-34459-11758 to Martin Wiedmann, Department of Food Science, Cornell University (Ithaca, NY).

\section{REFERENCES}

Andersen, H. J., L. H. Pedersen, F. M. Aarestrup, and M. Chriel. 2003. Evaluation of the surveillance program of Streptococcus agalactiae in Danish dairy herds. J. Dairy Sci. 86:1233-1239.

Barnum, D. A., and D. S. Fuller. 1953. Report on an outbreak of chronic mastitis in cattle caused by a Streptococcus of Lancefield's group G. Can. J. Comp. Med. 27:465-472.

Bergner-Rabinowitz, S., M. Ferne, S. Fleiderman, G. Ziv, A. Saran, and M. Winkler. 1981. Group G type X: A new antigenic combination in streptococci isolated from cases of bovine mastitis in Israel. Vet. Microbiol. 6:383-387.

Bert, F., C. Branger, B. Poutrel, and N. Lambert-Zechovsky. 1997. Differentiation of human and animal strains of Streptococcus dysgalactiae by pulsed-field gel electrophoresis. FEMS Microbiol. Lett. 150:107-112.

Bisharat, N., D. W. Crook, J. Leigh, R. M. Harding, P. N. Ward, T. J. Coffey, M. C. Maiden, T. Peto, and N. Jones. 2004. Hyperinvasive neonatal group B streptococcus has arisen from a bovine ancestor. J. Clin. Microbiol. 42:2161-2167.

Cefai, C., S. Ashurst, and C. Owens. 1994. Human carriage of methicillin-resistant Staphylococcus aureus linked with pet dog. Lancet 344:539-540.

Devriese, L. A., and J. Hommez. 1975. Epidemiology of methicillinresistant Staphylococcus aureus in dairy herds. Res. Vet. Sci. 19:23-27.

Devriese, L. A., J. Hommez, R. Kilpper-Balz, and K. Schleifer. 1986. Streptococcus canis sp. nov.: A species of group G streptococci from animals. Int. J. Syst. Bact. 36:422-425.

DeWinter, L. M., D. E. Low, and J. F. Prescott. 1999. Virulence of Streptococcus canis from canine streptococcal toxic shock syndrome and necrotizing fasciitis. Vet. Microbiol. 70:95-110.

Eberhart, R. J., and S. B. Guss. 1970. Group G streptococci in the udders of a Pennsylvania dairy herd. JAVMA 157:1195-1199.

Eberhart, R. J., P. L. LeVan, L. C. Griel, Jr., and E. M. Kesler. 1983. Germicidal teat dip in a herd with low prevalence of Streptococcus agalactiae and Staphylococcus aureus mastitis. J. Dairy Sci. 66:1390-1395. 
Facklam, R. 2002. What happened to the streptococci: Overview of taxonomic and nomenclature changes. Clin. Microbiol. Rev. $15: 613-630$

Hamilton, C. A., and D. M. Stark. 1970. Occurrence and characterization of Lancefield group $\mathrm{G}$ streptococci in bovine mastitis. Am. J. Vet. Res. 31:397-398.

Hassan, A. A., I. U. Khan, A. Abdulmawjood, and C. Lämmler. 2003. Development of PCR assays for detection of Streptococcus canis. FEMS Microbiol. Lett. 219:209-214.

Ikebe, T., S. Murayama, K. Saitoh, S. Yamai, R. Suzuki, J. Isobe, D. Tanaka, C. Katsukawa, A. Tamaru, A. Katayama, Y. Fujinaga, K. Hoashi, and H. Watanabe. 2004. Surveillance of severe invasive group-G streptococcal infections and molecular typing of the isolates in Japan. Epidemiol. Infect. 132:145-149.

Lewthwaite, P., H. K. Parsons, C. J. Bates, M. W. McKendrick, and D. H. Dockrell. 2002. Group G streptococcal bacteraemia: An opportunistic infection associated with immune senescence. Scand. J. Infect. Dis. 34:83-87.

Libertin, C. R., F. Leal, and D. S. Stein. 1988. Group G Streptococci: Susceptibility patterns and the effect of the inoculum size and growth phase on the bactericidal activity of penicillin. Diagn. Microbiol. Infect. Dis. 9:33-40.

Loeffler, S. H., T. J. Lam, H. W. Barkema, D. Scholten, A. L. Hessels, and A. M. van Gestel. 1995. The dairying veterinary approach to high bulk milk cell count caused by Streptococcus agalactiae. Tijdschr. Diergeneeskd. 120:458-463.

McDonald, T. J., and J. S. McDonald. 1976. Streptococci isolated from bovine intramammary infections. Am. J. Vet. Res. 37:377-381.

Miller, W. T., and J. O. Heishman. 1940. Bovine mastitis caused by unusual types of streptococci. Cornell Vet. 30:310.

National Mastitis Council. 1999. Laboratory Handbook on Bovine Mastitis. National Mastitis Council, Madison, WI.

National Committee on Clinical Laboratory Standards (NCCLS). 1997. Performance Standards of Antimicrobial Disk Susceptibility Tests. 6th ed. NCCLS, Wayne, PA.

Neave, F. K., F. H. Dodd, R. G. Kingwill, and D. R. Westgarth. 1969. Control of mastitis in the dairy herd by hygiene and management. J. Dairy Sci. 52:696-707.

Romer, O. 1948. The significance of group G streptococci in inflammation of the udder in cows. Biol. Abstr. 22:2519.

Scott, G. M., R. Thomson, J. Malone-Lee, and G. L. Ridgway. 1988. Cross-infection between animals and man: Possible feline transmission of Staphylococcus aureus infection in humans? J. Hosp. Infect. 12:29-34.

Sukhnanand, S., B. Dogan, M. O. Ayodele, R. N. Zadoks, M. P. J. Craver, N. B. Dumas, Y. H. Schukken, K. J. Boor, and M. Wiedmann. 2005. Molecular subtyping and population genetics of bo- vine and human Streptococcus agalactiae isolates. J. Clin. Microbiol. 43:1177-1186.

Sylvetsky, N., D. Raveh, Y. Schlesinger, B. Rudensky, and A. M. Yinnon. 2002. Bacteremia due to beta-hemolytic Streptococcus group G: Increasing incidence and clinical characteristics of patients. Am. J. Med. 112:622-626.

Takeda, N., K. Kikuchi, R. Asano, T. Harada, K. Totsuka, T. Sumiyoshi, T. Uchiyama, and S. Hosoda. 2001. Recurrent septicemia caused by Streptococcus canis after a dog bite. Scand. J. Infect. Dis. 33:927-928.

Wang, S. M., M. A. Deighton, J. A. Capstick, and N. Gerraty. 1999 Epidemiological typing of bovine streptococci by pulsed-field gel electrophoresis. Epidemiol. Infect. 123:317-324.

Watts, J. L., S. C. Nickerson, and J. W. Pankey. 1984. A case study of Streptococcus group G infection in a dairy herd. Vet. Microbiol. 9:571-579.

Whatmore, A. M., K. H. Engler, G. Gudmundsdottir, and A. Efstratiou. 2001. Identification of isolates of Streptococcus canis infecting humans. J. Clin. Microbiol. 39:4196-4199.

Wilson, D. J., R. N. Gonzalez, and H. H. Das. 1997. Bovine mastitis pathogens in New York and Pennsylvania: Prevalence and effects on somatic cell count and milk production. J. Dairy Sci. 80:2592-2598.

Woo, P. C., A. P. To, H. Tse, S. K. Lau, and K. Y. Yuen. 2003. Clinical and molecular epidemiology of erythromycin-resistant beta-hemolytic Lancefield group G streptococci causing bacteremia. J. Clin. Microbiol. 41:5188-5191.

Yildirim, A. O., C. Lämmler, R. Weiss, and P. Kopp. 2002. Phenoand genotypic properties of streptococci of serological group B of canine and feline origin. FEMS Microbiol. Lett. 212:187-192.

Zadoks, R. N., H. G. Allore, H. W. Barkema, O. C. Sampimon, Y. T. Gröhn, and Y. H. Schukken. 2001. Analysis of an outbreak of Streptococcus uberis mastitis. J. Dairy Sci. 84:590-599.

Zadoks, R. N., B. E. Gillespie, H. W. Barkema, O. C. Sampimon, S. P. Oliver, and Y. H. Schukken. 2003. Clinical, epidemiological and molecular characteristics of Streptococcus uberis infections in dairy herds. Epidemiol. Infect. 130:335-349.

Zadoks, R. N., R. N. Gonzalez, K. J. Boor, and Y. H. Schukken. 2004. Mastitis-causing streptococci are important contributors to bacterial counts in raw bulk tank milk. J. Food Prot. 67:26442650 .

Zaoutis, T., B. Schneider, M. L. Steele, and J. D. Klein. 1999. Antibiotic susceptibilities of group C and group G streptococci isolated from patients with invasive infections: Evidence of vancomycin tolerance among group G serotypes. J. Clin. Microbiol. $37: 3380-3383$. 